\title{
Evaluation of environmental sensitivity of the coastal plains shoreline to oil spills: Southwestern Sinai coastal plain, Egypt
}

\author{
Ahmed Wahid, Marguerite Madden \\ Center for Geospatial Research, Department of Geography, University of Georgia, GA 30602, \\ USA
}

Email: awahid@sci.psu.edu.eg

\begin{abstract}
Assessing the coastal Environmental Sensitivity Index (ESI) is very important for contingency planning for oil spills, especially for regions undergoing urban development. This study is an attempt to identify the sensitivity of the southeastern portion of the Gulf of Suez shoreline; a very promising area for economic development. Enhancing a methodology for calculating ESI in this work obtains more efficient results for environmental sensitivity assessment. This is accomplished by adding more detailed physical factors that may affect the ESI. The coastline is ranked according to factors controlling coastal resiliency to oil spills. These factors are categorized in three sets of data: 1) physical habitats of the coastline that determine the persistence of oil pollution and ease of cleaning and reclamation such as beach types, degree of exposure to waves, beach slope, wave directions and tidal flats (physical factors); 2) biological resources sensitive to oil (ecosystem factors); and 3) the types of human-use resources (socio-economic factors). Data used to determine these factors were collected from satellite images, field work and documentary information and were manipulated in a GIS environment using a geospatial arithmetic modeling to produce spatial environmental sensitivity maps of coastal shorelines. The studied shoreline of the southwestern Sinai coastal plain of Egypt has a wide range of sensitivity to oil spills ranges from very low to very high. The northern part of the shoreline is characterized by low sensitive beaches where the morphology and beach type play the dominant rule in reducing the sensitivity. It is composed mainly of high slope rocky beaches. The southern part is dominant by sandy tidal flat beaches and coral reefs communities that extend wider and shallower. This makes the southern beaches relatively more environmentally sensitive to oil spills.
\end{abstract}

Keywords: Geospatial, GIS, Oil Spills, Environmental Sensitivity Index, Sinai Egypt, Coastal Plains.

\section{INTRODUCTION}

An Environmental Sensitivity Index (ESI) mapping system assigns parameters that indicate the degree of vulnerability of the coastal environment to oil spills [16]. The basis of a coastal Vulnerability Index (VI) was set up by Gundlach and Hayes (1978) that was taken by the U.S. National Oceanic and Atmospheric Administration (NOAA) as the base for developing the ESI mapping system. The ESI mapping was applied with modification and development through time. With the development of Geographical Information Systems (GIS) and the increase of modeling capability of computer system, ESI mapping becomes more representable. The integration of remote sensing, GIS and environmental modeling is now widely accepted as desirable, if not essential $[11,18]$, as it is not only an efficient tool in presenting data, but also in analysis and modeling.

Oil spill contingency plans Since the 1960s are rapidly becoming commonplace to both regional and local levels in response to public concern for the environment [7, 8]. Caring for the response to oil spills is an important consideration for planning future development of the coastal areas. The offshore oil productivity and shipping in Egypt are becoming more important in recent times, especially in the Gulf of Suez. The production facilities in the Gulf of Suez yield 36 million tons of oil and gas annually [23]. Shipping incidents and oil spilling in the Gulf of Suez were reported in years 1982, 1989 and 1993 [1, 2, 17, 20, 23, 24]. Studying the response of the Egyptian coastal environment to oil spills increased in the last 3 decades with some difficulties, as usually there is lack of information about the impact of those spills on the coastal environment. The response to oil spills in Egypt has been based on experience and personal judgment rather than a rational, scientific approach [23]. However, the wide use of high resolution remotely sensed data with the GIS capability has facilitated the environmental sensitivity index (ESI) mapping and analysis. 


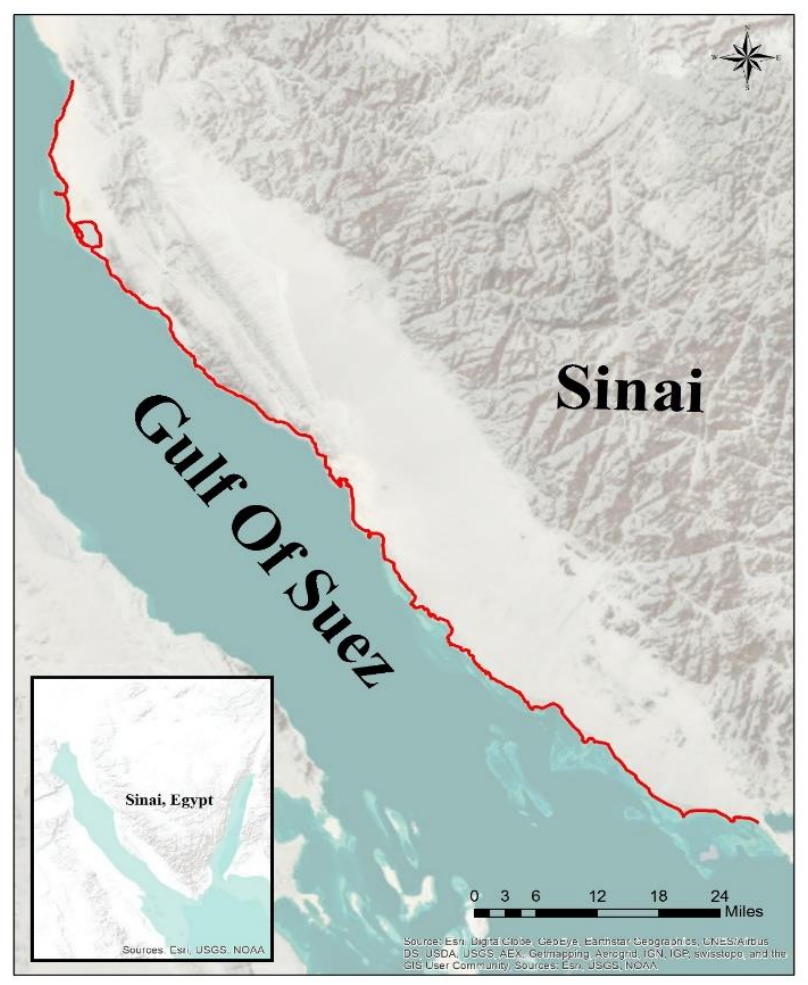

Figure 1. Location of the study area

Because of the unique marine and terrestrial environmental conditions along its coasts, more interest for mapping ESI has been focused on the Sinai Peninsula and Red Sea coasts. This is including a high biological diversity such as coral reefs, mangroves, rare wildlife species and a variety of coastal geomorphology from rocky to sandy, with both low and high relief topology with stable physical characters such as salinity, temperature and water quality $[3,4,6,27]$. Oil production and shipping always threaten the coasts of the Red Sea and Sinai with oil pollution, especially the Gulf of Suez where the majority of oil exploration and production is located. Most of the tourism and recreation sites in south Sinai are located on Ras Mohamed and the Gulf of Aqaba. The area of study is located in the southern part of the Gulf of Suez where both the sensitivity environment and oil production are located. South part is considered a natural geographical and environmental extension of Ras Mohamed as they share marine coral reefs and sandy beach characteristics. However, the southern part was always occupied by oil exploration and exploitation and the urban and tourism activities are concentrated in the north part of the plain. Now most of the oil activities are offshore. The Gulf of Suez and Red Sea coasts are rapidly becoming among the largest offshore oil production areas [9]. This in turn gave the chance for increasing development of the other economic activities such as tourism, recreation and fisheries.

The studied coastal plain extends along southwest Sinai, Egypt. It trends northwest-southeast with a length approximately $200 \mathrm{~km}$ (Figure 1). The southern part of the study area is characterized by sandy beached and fringing coral reefs, where rocky beaches.

\section{MATERIALS AND METHODS}

The procedure of preparing the ESI map of the study area depends mainly on the Environmental Sensitivity Index Guidelines produced by NOAA in 1997 and modified in 2003.
In this procedure, the coastline is ranked according to factors controlling coast sensitivity. Data collected for this work are from filed work, laboratory analysis, governmental reports and maps and previous works. Remote sensing and GIS techniques are used for extracting data, converting data sets to GIS combatable format and manipulating spatial data to modulate the sensitivity degree of the area coast to oil spills. The increasing use of GIS in ecological modeling calls for corresponding emphasis on upgrading, maintaining and environmental monitoring of relevant parameters and dynamics [22, 26]. Thus, seeking more accuracy and efficiency for mapping ESI, new factors are prepared in GIS format and added in the model to calculate sensitivity of the coastline.

Field data are an essential for ESI mapping of monitoring and control systems [25]. Field surveys were carried out in the study area during April 2004 to collect samples and document by writing reports and taking photographs of the features and information related to ESI. A total of 200 beach sand samples were collected along the beach of the study area from different coast forms (beaches, tidal flats and sabkhas).

Remote sensing also provides critical information for ESI. The coastline was extracted from ASTER satellite images as described in Wahid et al, 2008 and Landuse /land cover of the study area were defined after Wahid et.al., 2009. Additional point features such as marinas sea ports and oil platform were defined in Google Earth Plus as KML format and then exported as shapefiles to complete the information required for the analysis. Figure 2 shows the coastline and landuse features needed for sensitivity analysis of the study area. A DEM was also developed from stereo ASTER images and used for this ESI mapping. Online data nowadays provide researchers with a large supply of free and low cost data that are downloadable over the internet in GIS format. Google Earth Pro and GeoMapApp were used to complete data required for this ESI study of the study area. The bathymetric grid of the Gulf of Suez for example, was downloaded from Marine Geoscience 
Data System (MGDS) using their GeoMapApp free application. The bathymetry grid is resembled to $30-\mathrm{m}$ pixel resolution to be compatible with the DEM and derived slope raster layers. Contour lines of the bathymetry grid were extracted using the Spatial Analyst extension in ArcGIS (Figure 3).

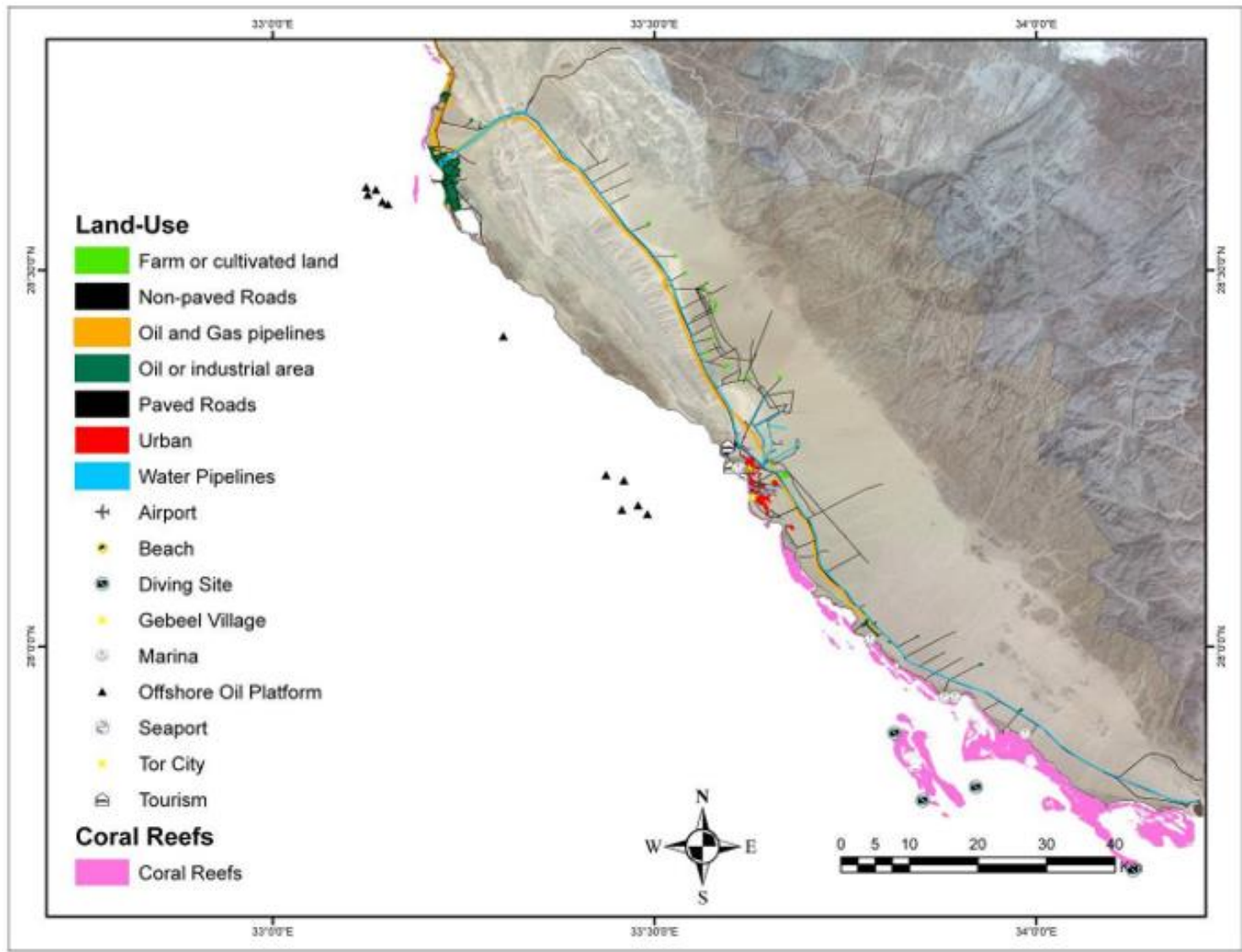

Figure 2. Landuse features onshore and offshore the studied plain

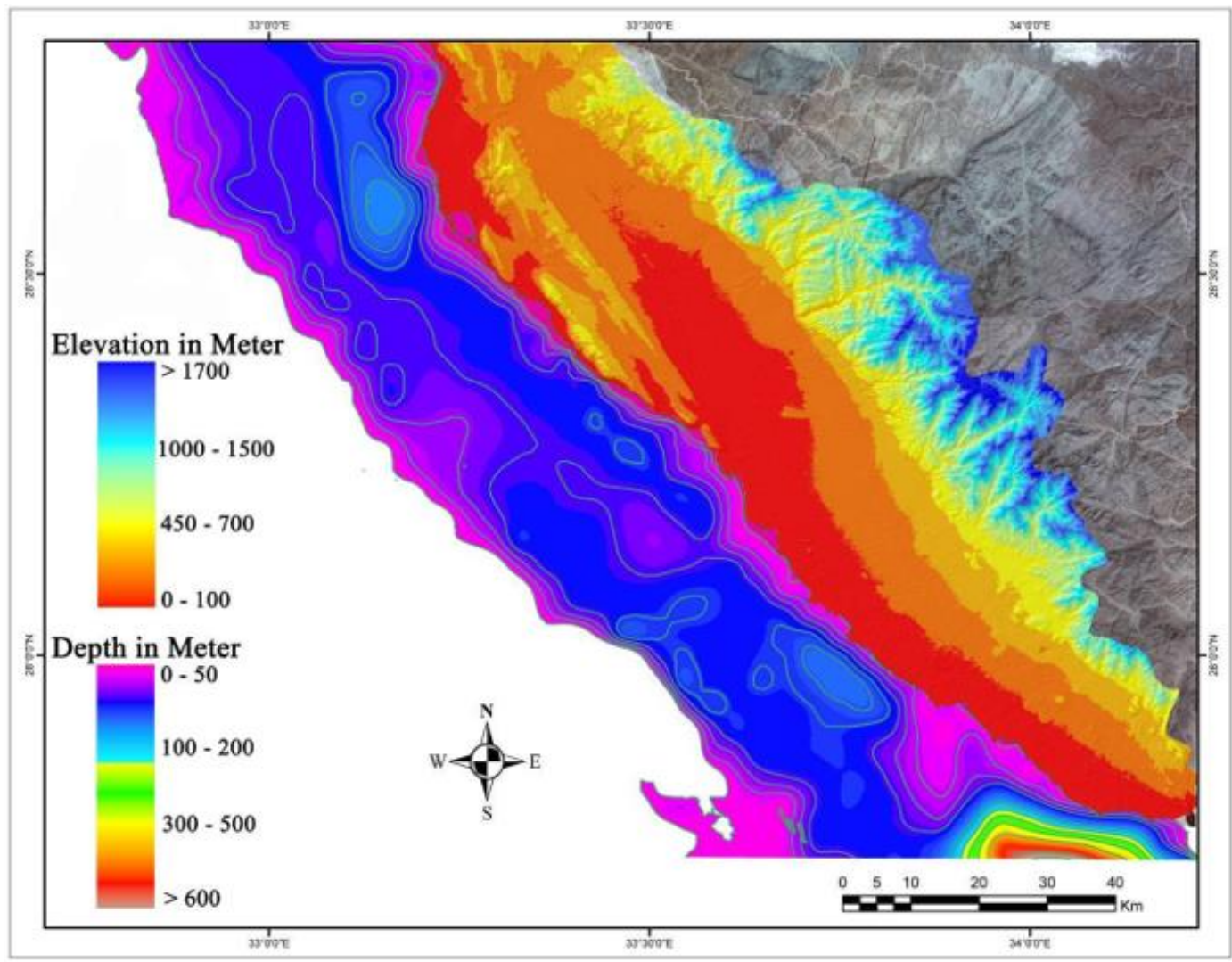

Figure 3. Elevation of land and depth of the Gulf of Suez along the study area 


\subsection{Parameters affecting coastline sensitivity}

According to the factors affect the sensitivity of the coastline, eight layers were prepared for coastal sensitivity analysis. These factors are:

1- Physical habitats layers
1. Beach types
2. Degree of exposure
3. Slope
4. Wave directions
5. Tidal flat

2- Biological resources layer (Ecosystem)

3- Human-use resources layer (Socio-economy)

4- Non-physical parameters layer

Each layer was categorized into sectors ranked from 1 to 10 according to the degree of sensitivity of each factor with 1 being the lowest and 10 the highest sensitivity. The way of preparing the layers and assigning sensitivity to each layer will be discussed in details in the next sections.

\subsubsection{Physical parameters}

The physical habitats of the coastline of the study area are represented in five vector format (shape files) layers:

\section{a) Beach types}

The beach type layer was digitized and attributed from a scanned geological map, an ASTER mosaiced image and field trip notes. The geological setting of the Gulf of Suez is the chief player in identifying the coastal environment of the area of study. The southerncoastal zone is characterized by tidalflat sandy beaches, wetlands and marshes, while the northern part is dominated by sandy, rocky and mixed (from fine sand to cobbles) beaches (Table 1 and Figure 4). It can be seen that $37.35 \%$ of the coast is composed of sandy beaches. Wetlands and marshes are also found on sandy beaches, it means that the majority of the coast component is sand. Rocky beaches consist of only $3.33 \%$ of the study area beaches where $20.88 \%$ of the coast is mixed beaches of sand, shells and rock fragments. Although rocky beaches are characterized by high biological diversity, they are less sensitive to oil spills. Oil on rocky shores is assumed to degrade relative rapidly [22]. This is because of the non-permeability attribute of the rocky beaches that make oil accumulate on the rock exposed to cleaning by waves. Wetlands and salt marches are the most sensitive environment to oil spills, as the oil may persist for years. In sandy beaches, oil is penetrated between sand grains and tends to persist the environment and greatly impact marine animal and plant life (Figure 4).

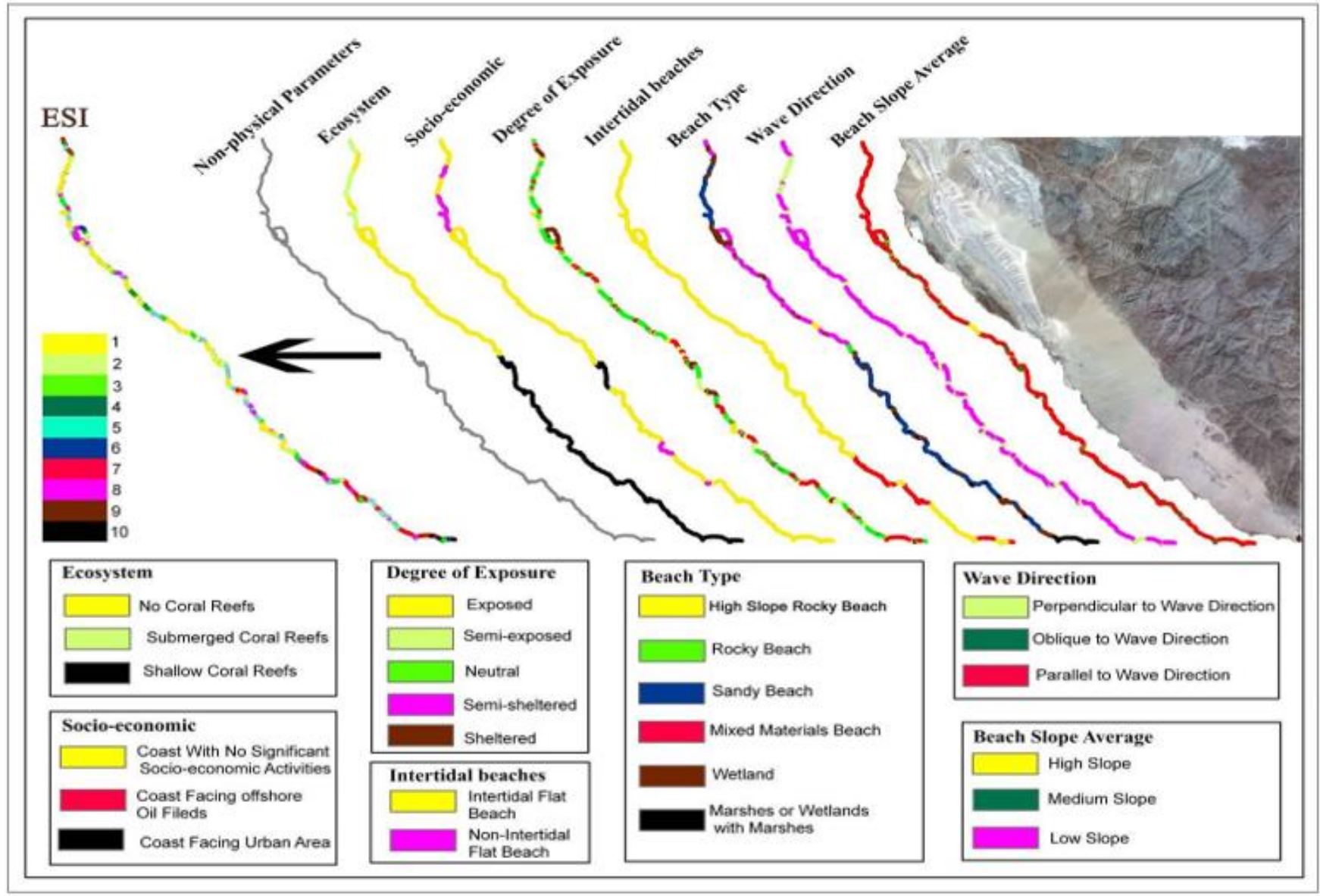

Figure 4. A sketch collecting all sensitivity parameters and the resulting Environmental Sensitivity Index (ESI) layer

\section{b) Exposure to waves}

The degree of exposure layer was digitized directly from the produced base map by manually differentiating the open from sheltered coastal segments. The coastline was classified into four classes related to the degree of exposure or shelter; exposed, semi-sheltered, sheltered and neutral. Geomorphologic character of the coastline is an important factor in determining the sensitivity of the shoreline. The shoreline exposed to wave and tidal activity is more subjected to natural cleaning, so that it is less sensitive than the sheltered one. Exposure habitats of the coastline indicate that $23.52 \%$ of the coastline is exposed to wave action, where $15.55 \%$ and $24.16 \%$ are sheltered to semi-sheltered and $36.69 \%$ look like straight and are thus neutral (Table 1 and Figure 4). 
Table 1. Percentages of each category for physical, biological and human-use parameters along the studied coastline

\begin{tabular}{|c|c|c|c|c|c|c|c|c|c|c|c|c|c|}
\hline \multicolumn{10}{|c|}{ Physical Parameters } & \multicolumn{2}{|c|}{ Ecosystem } & \multicolumn{2}{|c|}{ Socio-economic } \\
\hline \multicolumn{2}{|c|}{ Beach Type } & \multicolumn{2}{|c|}{ Exposure } & \multicolumn{2}{|c|}{ Slope } & \multicolumn{2}{|c|}{$\begin{array}{l}\text { Beach facing wave } \\
\text { direction }\end{array}$} & \multicolumn{2}{|c|}{ Tidal Beach } & \multirow[b]{2}{*}{$\begin{array}{l}\text { Ecosystem } \\
\text { type }\end{array}$} & \multirow[b]{2}{*}{$\%$} & \multirow[b]{2}{*}{$\begin{array}{c}\text { Socio- } \\
\text { economic }\end{array}$} & \multirow[b]{2}{*}{$\%$} \\
\hline $\begin{array}{c}\text { Beach } \\
\text { Type }\end{array}$ & $\%$ & $\begin{array}{l}\text { Exposure } \\
\text { to Waves }\end{array}$ & $\%$ & $\begin{array}{c}\text { Slope } \\
\text { degree }\end{array}$ & $\%$ & $\begin{array}{c}\text { Beach } \\
\text { Direction }\end{array}$ & $\%$ & $\begin{array}{c}\text { Tidal } \\
\text { and no- } \\
\text { tidal } \\
\text { beaches }\end{array}$ & $\%$ & & & & \\
\hline $\begin{array}{l}\text { Almost } \\
\text { vertical } \\
\text { rocky } \\
\text { beaches }\end{array}$ & 1.74 & Exposed & 23.59 & $\begin{array}{l}\text { Low } \\
\text { slope }\end{array}$ & 86.38 & E-W (oblique) & 0.24 & $\begin{array}{l}\text { Non- } \\
\text { tidal flat } \\
\text { beaches }\end{array}$ & 83.68 & $\begin{array}{l}\text { No coral } \\
\text { reefs }\end{array}$ & 38.69 & $\begin{array}{c}\text { No } \\
\text { significant } \\
\text { activities }\end{array}$ & 83.81 \\
\hline Rock & 1.59 & Neutral & 36.69 & $\begin{array}{l}\text { Moderate } \\
\text { slope }\end{array}$ & 10.02 & N-S (oblique) & 0.31 & $\begin{array}{c}\text { Tidal } \\
\text { flat } \\
\text { beaches }\end{array}$ & 16.32 & $\begin{array}{l}\text { Shallow } \\
\text { coral reefs }\end{array}$ & 51.62 & $\begin{array}{l}\text { Oil fields } \\
\text { and } \\
\text { utilities }\end{array}$ & 10.15 \\
\hline Mixed & 20.88 & $\begin{array}{c}\text { Semi- } \\
\text { sheltered }\end{array}$ & 24.16 & $\begin{array}{l}\text { High } \\
\text { slope }\end{array}$ & 3.60 & $\begin{array}{c}\text { NE-SW } \\
\text { (perpendicular) }\end{array}$ & 18.17 & & & $\begin{array}{l}\text { Submerged } \\
\text { coral reefs }\end{array}$ & 9.69 & $\begin{array}{l}\text { Important } \\
\text { human use } \\
\text { resources }\end{array}$ & 6.05 \\
\hline Sand & 37.35 & Sheltered & 15.55 & & & $\begin{array}{c}\text { NW-SE } \\
\text { (parallel) }\end{array}$ & 81.28 & & & & & & \\
\hline $\begin{array}{l}\text { Wetlands } \\
\text { (sabkha } \\
\text { and } \\
\text { marshes) }\end{array}$ & 27.27 & & & & & & & & & & & & \\
\hline Marshes & 5.24 & & & & & & & & & & & & \\
\hline $\begin{array}{l}\text { Wetland } \\
\text { and } \\
\text { marshes }\end{array}$ & 5.93 & & & & & & & & & & & & \\
\hline
\end{tabular}

\section{d) Beach facing wave direction}

The wave facing layer was produced by segmenting the base map according how the beach faces the prevailing wind direction; perpendicular, oblique or parallel. Direction of coastline facing the wave strikes has significant effects on the self-cleaning ability of the beach. Wave strength and direction depend on the wind force, direction and duration. The dominant winds component at the study area is NW with about $60 \%$ total annual duration of effective winds. The coast segments that directly face (perpendicularly) the wave direction are subjected to natural greater cleaning than those that are oblique to waves or those that are parallel to waves. The parallel coastlines to wave represent $81.28 \%$ of the studied coast, whereas $18.17 \%$ is the perpendicular coasts. The oblique coast segments are less than 1\% (Table 1 and Figure 4).

\section{e) Tidal and non-tidal flat beaches}

The tidal flat layer was digitized depending mainly on field visits and visual classification from ASTER image and Google Earth imagery. The coastline is segmented into two types of coast: tidal flat beach and non-tidal flat beaches. Tidal flat beaches are more accessible to oil spills than non-tidal flat beaches. However, other factors may contribute in the sensitivity of the tidal beaches such as the degree of exposure. A total of $16.32 \%$ of the study area beaches are of tidal flat kind and concentrated mainly at the southern part.

2.1.2 Ecosystem parameter

Biological resources layer (ecosystem) was created in relation to the coral reefs communities in the study area water.
Coral reefs was extracted from the classified ASTER image, converted to vector format and updated manually from recent imagery of Google earth. The coastline of the study area was classified according to the nature and existing of the coral reefs into three classes; submerged coral reefs, shallow coral reefs and no coral reefs.

The Gulf of Suez is an abandoned rift basin with less than 100-meter water depths [19]. This makes the coral reefs of the Gulf of Suez less developed than Gulf of Aqaba and Red Sea which are much deeper. However, the western coast of the Gulf of Suez reefs are more developed and form a fringing reef that extends form $50 \mathrm{~km}$ south of Suez to Ain-Sukhna that extends 30 - 40 m offshore and sloping from 1 - 5 m depth [24]. These reefs enrich the ecosystem and the economic value of the study area. Coral reefs are tremendously important economic resources, supporting numerous recreational activities, tourism, fisheries, and protecting shorelines [15]. The coral reefs fringing off the shore of the study area were extracted from the classified ASTER image and mapped in Figure 2. Oil spills are poisonous to coral reefs through exposure to hydrocarbon. The most threatened damage is by direct contact of oil to reefs which happens for the shallow coral reefs communities. Sink oil or dissolved toxic oil components can affect the submerged coral reefs.

The coastline of the study area was marked and ranked according to the presence of coral reefs and whether coral reefs are shallow or submerged. The shallow reefs are found in the southern part and extend along $51.62 \%$ of the coastline, 
whereas the submerged coral extend along $9.69 \%$ and are concentrated in the north. A total of $38.69 \%$ of the coastline does not have coral reefs (Table 1 and Figure 4).

2.1.3 Socio-economic parameter

Human-use resources (socio-economic) were extracted from landuse-landcover classified maps and/or digitized manually from scanned topographic maps (scale 1:50000) and represented in forms of polygons, polylines, and points. Google Earth Plus was used efficiently in this procedure where some features were digitized on screen, saved as kml files and then imported to ArcGIS as in shapefiles format (Figure 2 and 4). Human Human-use resources are those places that are important to people and normally divided into four major components [14]:

- High-use recreational and shoreline access areas: such as boat ramps, marinas, recreational beaches, and sportfishing and diving areas;
- Management or protected areas: such as national parks, marine sanctuaries, national wildlife refuges, preserves, and reserves;

- Resource extraction sites: such as aquaculture sites, locations of subsistence and commercial fisheries, log storage sites, mining leases, and surface water intakes;

- Archaeological and historical locations.

The high impact human use resources features are concentrated in the southern part where El-Tor city is located. It represents about $6.05 \%$ of the coastline and the common activities are recreation, shipping, marinas and fishing (Figure 2 ). Other places in the north and south are oil production and utilities places which extend about $10.15 \%$ (Table 1 and Figure 4).

Physical, biological and human-use resources parameters can exist all in one part of the beach. Figure 5 shows examples of the interference of two or several kinds of parameters in one portion of the coastline.

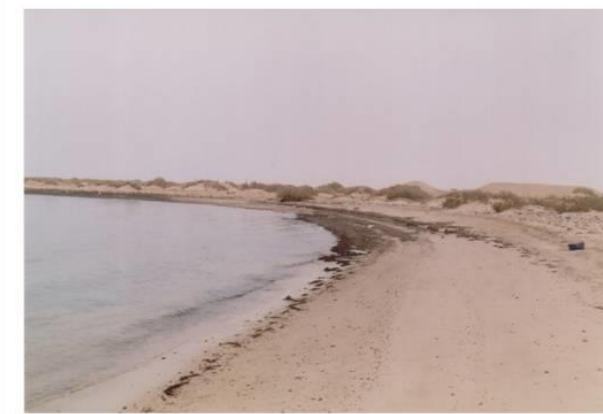

(1)

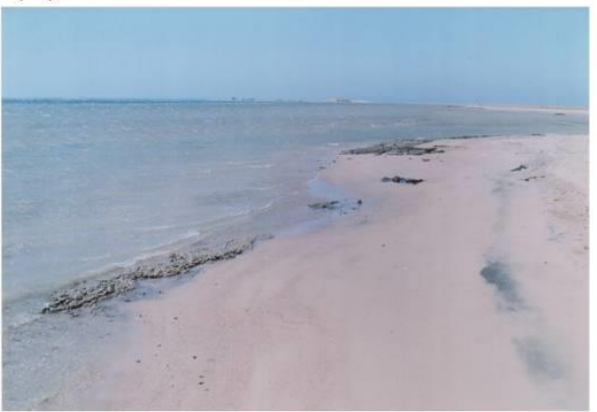

(3)

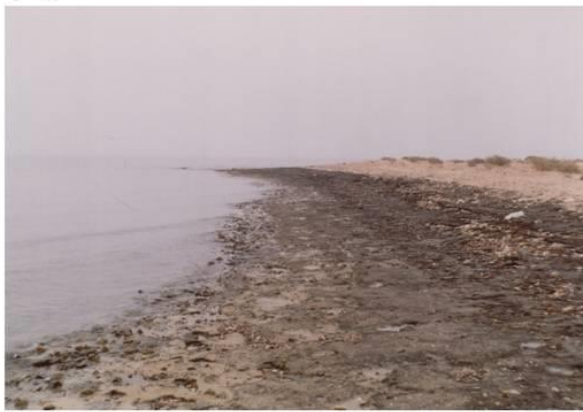

(5)

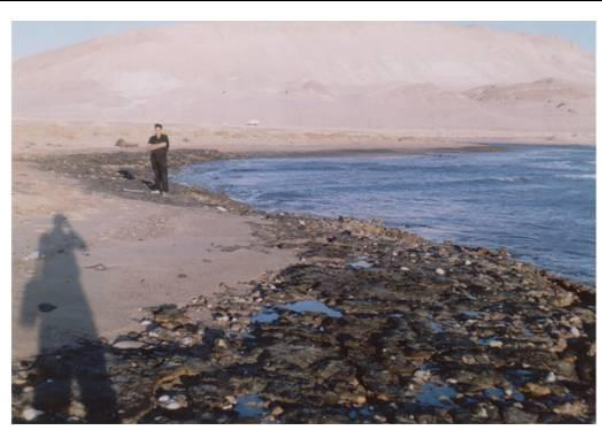

(2)

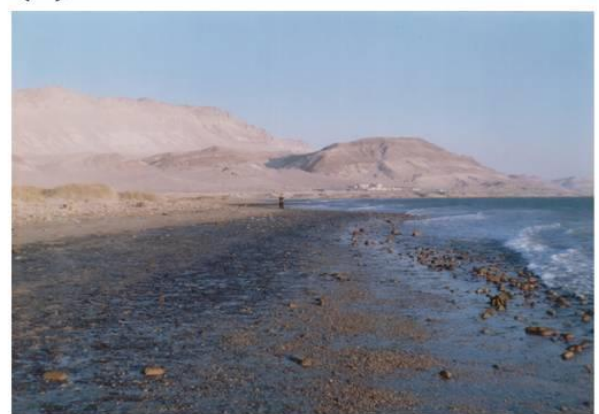

(4)

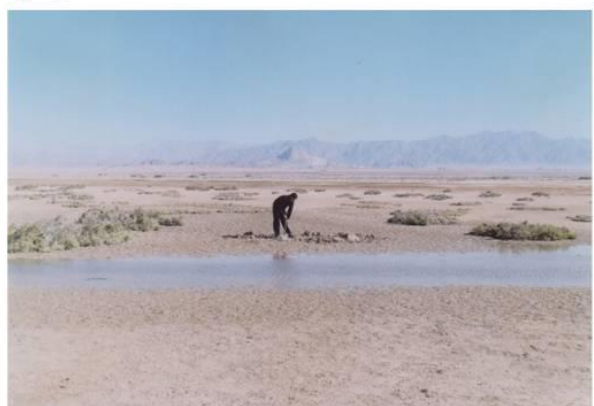

(6)

(1) Sheltered, low slope, sandy beach: high ESI

(2) Gravelly, moderately slope, sheltered beach: medium to high ESI

(3) Tidal flat beach with shallow fringing coral reef: high to very high ESI

(4) Mixed tidal flat beach: medium to very high ESI

(5) Gravelly non-sheltered beach: medium to high ESI

(6) Sabkha (wetland) and marshes beach: high to very high ESI

Figure 5. Types of coastline parameters related to coastal sensitivity 


\subsubsection{Nonphysical parameters}

To have an overall sensitivity delineation of the coast, other non-physical factors should be taken into consideration. Moe et al. (2000) defined environmental vulnerability as the significance of damage on a given ecosystem component or natural resource that potentially can be generated by a given disturbance event in the short, as well as in the long term. The sensitivity also can be affected by other factors regarding scientific, ecological and recreational values [3, 12, 20, 21]. Table 2 shows the non-physical factors and their weights to sensitivity response.

Table 2. Non-physical sensitivity weight rankes after El-Gamily et al. (2001) and Lotfy (2004)

\begin{tabular}{|c|c|c|c|c|c|c|c|c|c|c|c|c|c|}
\hline \multirow{2}{*}{ Shoreline Habitats } & \multicolumn{3}{|c|}{ Expected Damage } & \multicolumn{3}{|c|}{$\begin{array}{c}\text { Economic } \\
\text { /Recreation Value }\end{array}$} & \multicolumn{3}{|c|}{ Scientific Value } & \multicolumn{3}{|c|}{ Ecological Value } & \multirow{2}{*}{$\begin{array}{l}\text { Total } \\
\text { Score }\end{array}$} \\
\hline & Val. & Wt. & Sc. & Val. & Wt. & Sc. & Val. & Wt. & Sc. & Val. & Wt. & Sc. & \\
\hline Rocky ridge & 1 & 3 & 3 & 1 & 2 & 2 & 1 & 2 & 2 & 1 & 3 & 3 & 10 \\
\hline Sandy Beach & 2 & 3 & 6 & 2 & 2 & 4 & 1 & 2 & 2 & 1 & 3 & 3 & 15 \\
\hline Mixed Beach & 3 & 3 & 9 & 2 & 2 & 4 & 1 & 2 & 2 & 2 & 3 & 6 & 21 \\
\hline $\begin{array}{c}\text { Wetland and } \\
\text { Marshes }\end{array}$ & 4 & 3 & 12 & 1 & 2 & 2 & 2 & 2 & 4 & 3 & 3 & 9 & 27 \\
\hline Tidal flat & 5 & 3 & 15 & 2 & 2 & 4 & 1 & 2 & 2 & 2 & 3 & 6 & 27 \\
\hline Shallow Coral Reefs & 6 & 3 & 18 & 4 & 2 & 8 & 4 & 2 & 8 & 4 & 3 & 12 & 46 \\
\hline
\end{tabular}

\subsection{Environmental sensitivity index analysis}

To define the sensitivity of a coast, both parameters representing the nature and value of the coast were overlaid. Using the ArcGIS model builder, a simple model was created to compute the sensitivity degree along the studied coastline. The model is applied to physical, ecosystem, socio-economic and nonphysical parameters. A Flow chart in Figure 6 maps the processes of ESI model. The model steps start with converting all vector data to raster. These raster data were reclassified with numeric values reflect the relationship between each parameter and sensitivity degree as shown in Figure 4. For example, exposed beach takes low value, whereas sheltered ones take high values. The last procedure is to overlay the reclassified data in an arithmetic process, where the output of an operation is the input of the next one. Overlaying the physical parameters (multiplying) produces a grid that represents the coastline sensitivity layer. The result of the overlay process is considered to be the local Relative Sensitivity Index Map (RESI) of the shoreline habitats [20]. This RESI map is the map that refers to the sensitivity of the shoreline regarding the physical habitats. The physical and non-physical criteria are overlaid in concepts of map algebra to produce the ESI map of the study area (Figure 4). Other spatial data such as utilities, tourism sites and urban areas are added to the map to produce the final layout of ESI map of the study area (Figure 7).

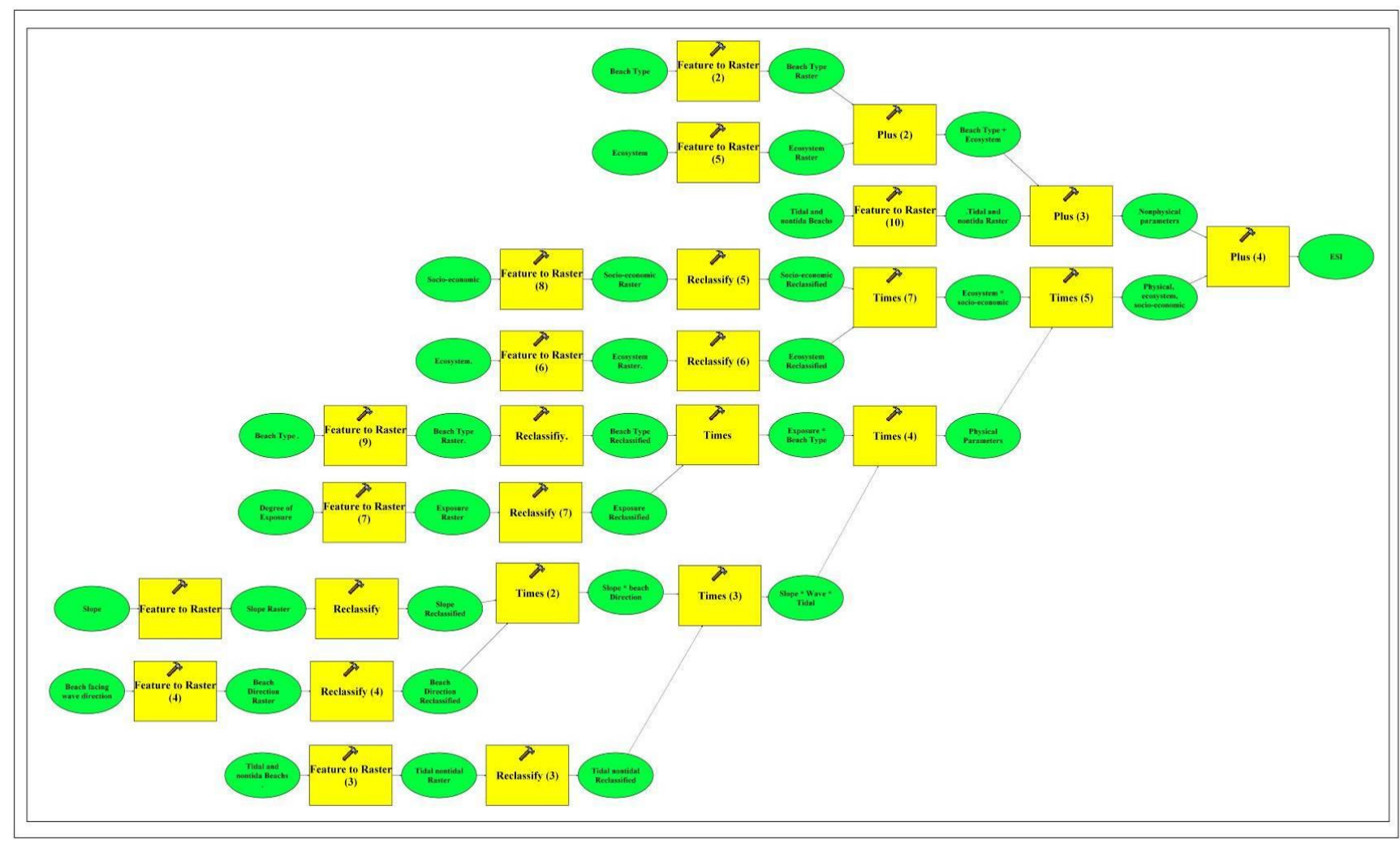

Figure 6. The flowchart of arithmetic geospatial model for defining the ESI for the study area 


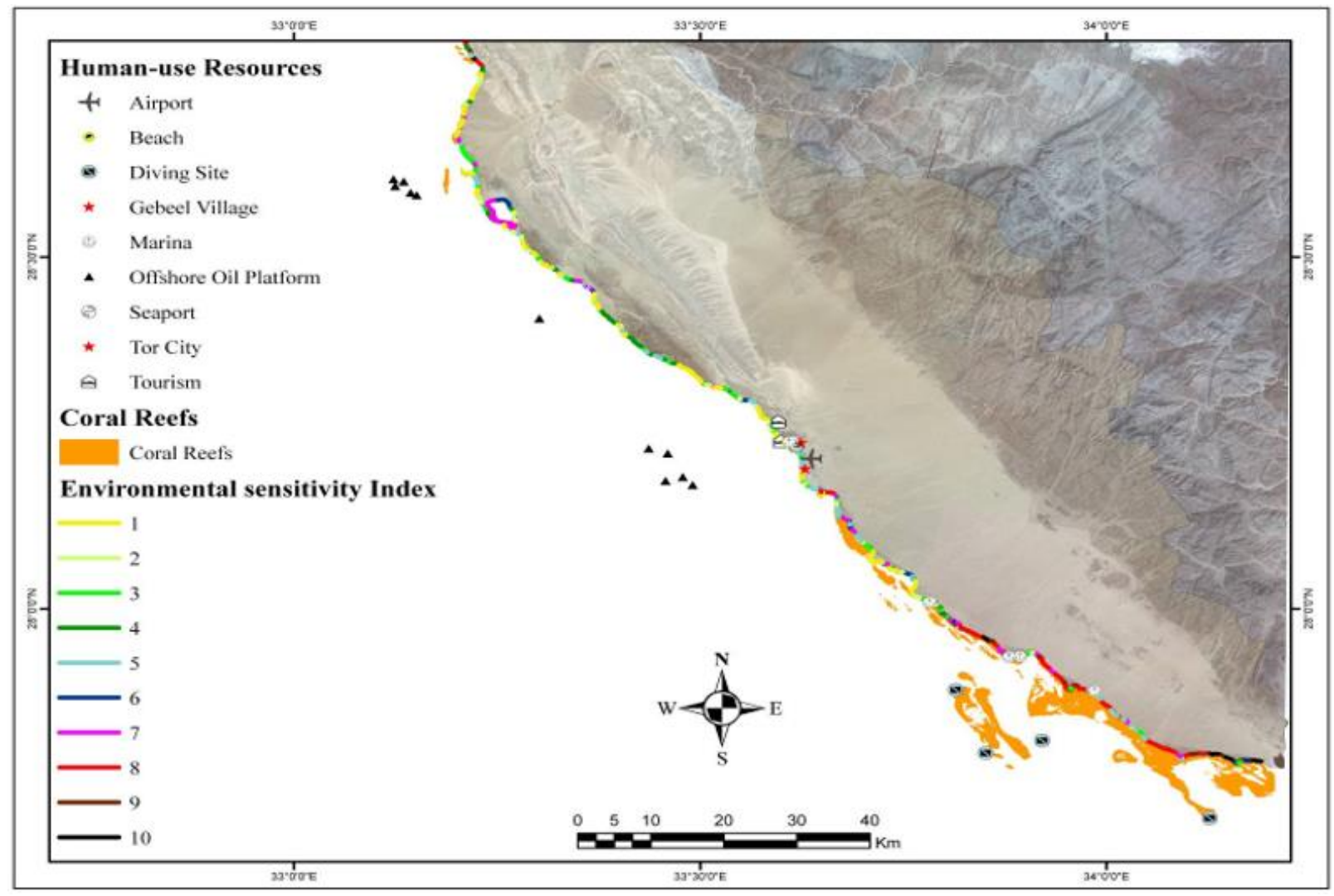

Figure 7. Final Environmental Sensitivity Index map of the studied coastal plain

\section{RESULTS AND DISCUSSION}

The aim of defining the environmental sensitivity index to oil spills is to predict the impact of the oil components to the coast environment. This impact is related to the nature and the value of the coast. The geological setting of the Gulf of Suez is the chief player in identifying the coastal environment of the area of study. The studied area is structurally controlled. It is a secondary rift basin which is a part of the intra-continental rift (Red Sea-Gulf of Suez rift system) began in the late Oligocene and separated the Sinai minor plate, and dominated by two large NW-SE trending fault systems- the Rift Border Fault system and the Costal Range Fault system define halfgraben $[10,13,21]$. This sunken half-graben was filled with materials drained from the south central Sinai mountainous range. This geological history made the studied plain a lowland of $>100 \mathrm{~m}$ asl and gently sloping towards the Gulf of Suez [29, 30]. The southern coastal zone is characterized by tidal-flat sandy beaches, wetlands and marshes where the northern part is dominated by sandy, rocky and mixed (from fine sand to cobbles) beaches. The classification of the shoreline according to physical parameters affecting the sensitivity of the studied shoreline are summarized and compiled in Table 1. It can be seen that $37.35 \%$ of the coast is sandy beaches. Wetlands and marshes are also found on sandy beaches, it means that the majority of coast component is sand. Rocky beaches consist $3.33 \%$ of the study area beaches where 20.88 of the coast is mixed beaches of sand, shells and rock fragments. Although, rocky beaches are characterized by the high biological diversity, it is less sensitive to oil spills. Oil on rocky shores is assumed to degrade relative rapidly [22]. This is because of the non-permeability attribute of the rocky beaches that make oil accumulated on the rock exposed to cleaning by waves.
Wetlans and salt marches are the most sensitive environment to oil spills, as the oil may persist for years. In sandy beaches, oil is penetrated between sand grains. Penetration depends on grain size, permeability and sorting of the sand. The Grain size distribution analysis result shows that the southern part of the study area has fine grain sizes and increase gradually northward [28]. Gundlach and Hayes, 1978 I stated that in fine graind sand beaches oil doesn't penetrate into the sediment and mechanical removal may be needed, where in coarse grained beaches oil may sink and/or be buried rapidly that makes removal is more difficult. So that the coastline of consideration from grain size point is more sensitive northward than southward.

Geomorphologic character of the coastline is an important factor in determining the sensitivity shoreline. The shoreline exposed to wave and tidal activity is more subjected to natural cleaning, so that it is less sensitive than the sheltered one. Exposure habitats of the coastline indicate that $23.52 \%$ of the coastline is exposed to wave action, where $15.55 \%$ and $24.16 \%$ are sheltered to semi-sheltered. $36.69 \%$ are look like straight (Figure 4 and Table 1). Direction of coastline facing the wave strikes has significant effects on the self-cleaning ability of the beach. Wind data of El-Tor meteorological station were classified and presented graphically in order to delineate the prevailing wind regime in form of an annual wind rose (Figure 8). Wave strength and direction depend on the wind force, direction and duration. The dominant winds component at the study area is NW with $60 \%$ total annual duration of effective winds. The coast segment that directed facing perpendicularly the wave direction are subjected to natural cleaning than those are oblique to wave than those are parallel to it. The parallel coastlines to wave represent $81.28 \%$ of the studied coast, where $18.17 \%$ is the perpendicular coasts. 
The oblique coast segments are less than 1\% (Figure 4 and Table 1). Tidal flat beaches are more accessible to oil spills than non-tidal flat beaches. However it depends on other factors like the degree of exposure and grain size. $16.32 \%$ of the study area beaches are tidal flat kind and concentrated mainly at the southern part. Shoreline slope has a pronounced effect on wave reflection and breaking where the steep intertidal beaches break or even reflect the coming waves that enhance natural cleanup, and gentle intertidal zones promote dissipation of wave energy further offshore, and in which oil remain longer $[14,20]$. The study area is generally of gentle slope $(86.38 \%)$, the moderately slope beaches are $10.02 \%$ of the whole shoreline, where the steep slope beaches represent only $3.6 \%$ and concentrated in the northern part (Figure 4 and Table 1).

The Gulf of Suez is an abandoned rift basin with less than 100-meter water depths [19]. This makes the coral reefs of the Gulf of Sues are less developed than Gulf of Aqaba and Red See which are much deeper. This makes the On the western coast of the Gulf of Suez reefs are more developed, forming a fringing reef that extends form $50 \mathrm{~km}$ south of Suez to AinSukhna that extends $30-40$ m offshore and sloping from $1-5$ $m$ depth [24]. These reefs enrich the ecosystem and the economic value of the study area. Coral reefs are tremendously important economic resources, supporting numerous recreational activities, tourism, fisheries, and protecting shorelines [15]. The Coral reefs fringing off the shore of the study area are extracted from the Aster image and mapped in Figure 2. Oil Spills are poison coral reefs through hydrocarbon. The most threatened damage is by direct contact of oil to reefs which happens for the shallow coral reefs communities. Sink oil or dissolved toxic oil components can affect the submerged coral reefs. Coastline of the study area is marked and ranked according to the presence of coral reefs and whether coral reefs is shallow or submerged. The shallow reefs are found in the southern part where the submerged are in the north.

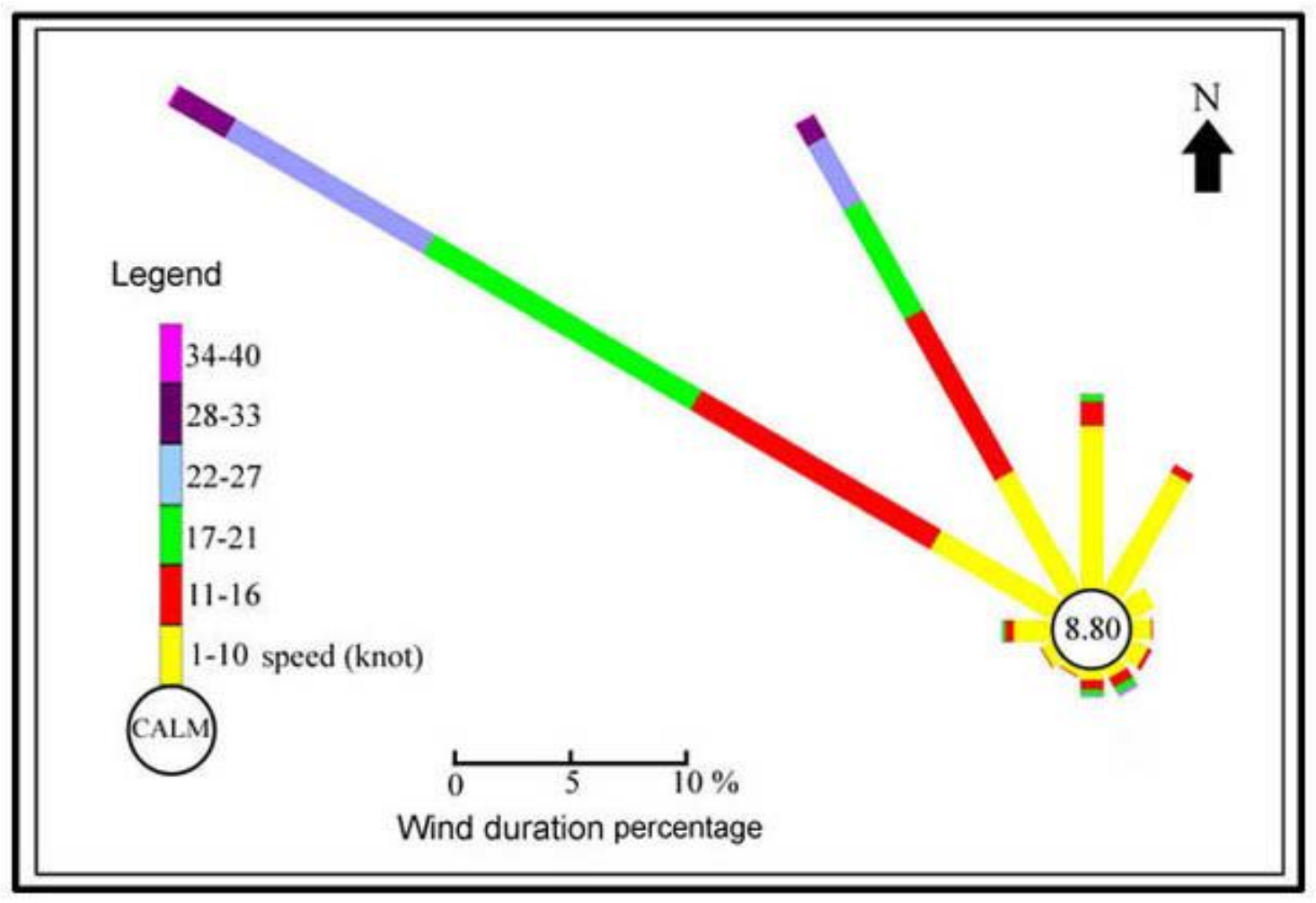

Figure 8. Wind rose represents the wind regime of the study area

In general, it can be said that the coastline of the area of study has a wide range of sensitivity from low to very high sensitivity. North of El-Tor is predominated by low to medium sensitivity coastlines. This is because this part is characterized by high slope rocky beaches and the coral reefs in this area are submerged. Also, the socio-economic activities are not common in this part of the area. However, there are some coast segments that have high sensitivity where factors are gathering to increase it. The southern part is characterized by tidal flat beaches, with moderate to low slope and the presence of wetlands, marshes and fringing coral reefs. Also, most of the socio-economic activities are concentrated in the southern part. The combinations of these factors increase the sensitivity index values of beaches of southward. Some sectors that was expected to have high sensitivity rank, has low to medium value. For example, the coast of El-Tor city is characterized by high socio-economic activities that supposed to make is highly sensitive to oil spills, however it has range 1 to 5 range of sensitivity. This could be attributed to the domination of other physical factors that reduce the accumulation of oil spills and increase the possibility of easy clean up. Also, some coast segments that facing shallow coral reefs has very low sensitivity value that could be related to the high presence of factors lowering the sensitivity of these parts. So that it is highly recommended to consider the individual rank of each physical factor along with the final ESI map.

\section{CONCLUSIONS}

The study area is a coastal plain that extends $\sim 200 \mathrm{~km}$ along the Gulf of Suez. Oil activities on the Gulf of Suez such as oil exploration and oil tanker can expose the coastline environment of the study area to oil pollution from expected 
oil spills. Using GIS and remotely sensed data and introducing more detailed information about the factors affecting the shoreline sensitivity make great enhancement for the ESI mapping. These enhancements to the ESI mapping concept make it more effective for developing contingency plans before an oil spill and making management decisions immediately after such a spill [11]. Three more maps were created for giving more details about the physical parameters; coast directions in relation to wave directions, grain size of beach sediments and tidal flat beaches. Arithmetic model is the best for manipulating the sensitivity layers to create the final ESI map.

The studied coastline is considered a moderate to high sensitive area to oil spills. Geomorphologic setting of the study area play important role in ranking the different sites of its coastline. The existing of shallow fringing coral reefs in the southern part along with the wetlands and marshes and socioeconomic activity increase the sensitivity of the southern beaches to the highest ranks. The presence of the coastal mountainous ranges in the northern part increases the distribution of rocky and mixed grain size beaches. The low sensitivity beaches are more developed in the northern part than the southern.

There is a lack of the biological data for the area under consideration. More biological research work is needed to provide more information for ESI mapping.

It is important to provide the project planners and decision makers with the whole data set, including the individual ranking maps for each factor that affect the sensitivity of the coastline.

\section{REFERENCES}

[1] Abou Zaid M. (2000). Overview of the status of Red Sea coral reefs in Egypt (unpublished report), p. 39.

[2] Alves T.M., Kokinou E., Zodiatis G., Lardner R., Panagiotakis C., Radhakrishnan H. (2015). Modelling of oil spills in confined maritime basins: The case for early response in the Eastern Mediterranean Sea, Environmental Pollution, Vol: 206, pp. 390-399. DOI: 10.1016/j.envpol.2015.07.042

[3] El-Gamily H.I., Nasr S., El-Raey M. (2001). An assessment of natural and human-induced changes along Hurghada and Ras Abu Soma coastal area, Red Sea, Egypt, International Journal of Remote Sensing, Vol. 22, No. 15, pp. 2999-3014.

[4] El Sherbiny A.H., Sherif A.H., Hassan A.N. (2006). Model for environmental risk assessment of tourism project construction on the Egyptian Red Sea Coast, Journal of Environmental Engineering, Vol. 132, No. 10 , pp. 1272-1281. DOI: 10.1061/(ASCE)07339372(2006)132:10(1272)

[5] Folk R.L., Ward W.C. (1957). Brazose river bar: A study on the significance of grain size parameters, Journal of Sedimentary Petrology, Vol. 27, pp. 3-26.

[6] Frihy O.E., Hassan A.N., El Sayed W.R., Iskander M.M., Sherif M.Y. (2006). A review of methods for constructing coastal recreational facilities in Egypt (Red Sea), Ecological Engineering, Vol. 27, pp. 1-12.

[7] Agudelo G., Diego L., Bernal N., Alberto R., Mojica I., Marcela D., Vargas G., María A., Erich G. (2015). Environmental sensitivity index for oil spills in marine and coastal areas in Colombia, Ciencia, Tecnología y Futuro, Vol. 6, No. 1, pp. 17-28.

[8] Gundlach E.R., Hayes M.O. (1978). Vulnerability of coastal environments to oil spill impacts, Marine Technology Society Journal, Vol. 12, pp. 18-27.

[9] Hanna R.G.M. (1995). An approach to evaluate the application of the vulnerability index for oil spills in tropical Red Sea environments, Spill Science and Technology Bulletin, Vol. 2, No. 2, pp. 171-186.

[10] Jackson C.A.L., Gawthorpe R.L., Sharp I.R. (2006). Style and sequence of deformation during extensional fault-propagation folding: Examples from the Hammam Faraun and El-Qaa fault blocks, Suez Rift, Egypt, Journal of Structural Geology, Vol. 28, pp. 519-535. DOI: $10.1016 /$ j.jsg.2005.11.009

[11] Jensen J.R., Ramsey E.W., Holmes J.M., Michel J., Savitsky B., Davis B.A. (1990), Environmental sensitivity index (ESI) mapping for oil spills using remote sensing and geographic information system technology, In Intl. J. of Geographic Information Systems, Vol. 4, No. 2, pp. 181-201.

[12] Coral Reef Management Handbook (1984). Kenchington R.A. Hudson E.T., UNESCO, Paris, France.

[13] Khalil S. (1998). Tectonic evolution of the eastern margin of the Gulf of Suez, Egypt. PhD Thesis, Royal Holloway, University of London, p. 348.

[14] Environmental Sensitivity Index Guidelines Version 3 (2002). NOAA, Seattle, USA, 192.

[15] Yender, R., Michel, J., Shigenaka, G., \& United States. (2010). Oil spills in coral reefs: Planning \& response considerations. Washington, D.C.: U.S. Dept. of Commerce, National Oceanic and Atmospheric Administration, National Ocean Service, Office of Response and Restoration.

[16] NOAA, (2017). Environmental Sensitivity Index (ESI) Maps, from https://response.restoration.noaa.gov/maps-and-spatialdata/environmental-sensitivity-index-esi-maps.html, accessed on 21 Dec. 2017

[17] ITOPF (2012) Country Profiles. A Summary of Oil Spill Response Arrangements and Resources Worldwide, from http://www.itopf.com/fileadmin/data/Documents/Coun try_Profiles/profiles.pdf, accessed on 22 Dec. 2017

[18] Li Y., Brimicombe A.J., Ralphs M.P. (2000). Spatial data quality and sensitivity analysis in GIS and environmental modelling: The case of coastal oil spills, Computers, Environment and Urban Systems, Vol. 24, pp. 95-108. DOI: 10.1016/S0198-9715(99)00048-4

[19] Lindquist S.J. (1998). The Red Sea basin provinceSudr-Nubia and Maqna petroleum systems, U.S. Geological Survey Open File Report.

[20] Lotfy I.N. (2004). GIS-based Environmental Sensitivity Index (ESI) mapping for oil spills: Case study in Sharm El-Sheikh, Egypt. MSc, Universiteit Gent Vrije Universiteit Brussel Belgium, p. 114

[21] McClay K.R., Nichols G.J., Khalil S., Darwish M., Bosworth W. (1998). Extensional tectonics and Sedimentation, eastern Gulf of Suez, Egypt. In: purser, B and Bosence., D.W.J. (eds), Sedimentation and tectonics of Rift Basins; Red Sea-Gulf of Aden, Chapman and Hall, London, pp. 223-238. 
[22] Moe K.A., Skeie G.M., Brude O.W., LØvås S.M., NedrebØ M., Weslawsk M.J. (2000). The svalbard intertidal zone: A concept for the use of GIS in applied oil sensitivity, vulnerability and impact analyses, Spill Science \& Technology Bulletin, Vol. 6, No. 2, pp. 187 206. DOI: $\underline{10.1016 / \mathrm{S} 1353-2561(00) 00038-4}$

[23] Nasr P., Smith E. (2006). Simulation of oil spills near environmentally sensitive areas in Egyptian coastal waters, Water and Environment Journal, Vol. 20, pp. 11-18. DOI: 10.1111/j.1747-6593.2005.00013.x

[24] Pilcher N., Abou Zaid M. (2000). The status of coral reefs in Egypt, Townsville, QLD: Global coral reef monitoring network.

[25] Schiller H., Bernem V.C., Krasemann H. (2005). Automated classification of an environmental sensitivity index, Environmental Monitoring and Assessment, Vol. 110, pp. 1-3+291-299. DOI: $\underline{10.1007 / \mathrm{s} 10661-005-8041-8}$

[26] Tirmizi S.T., Tirmizi S.R.U.H. (2017). GIS based risk assessment of oil and gas infrastructure in Sindh, Pakistan, Environmental and Earth Sciences Research
Journal, Vol. 4, No. 3, pp. 55-59. DOI: 10.18280/eesrj.040301

[27] Vanderstraete T., Goossens R., Ghabour T.K. (2004). Coral reef habitat mapping in the Red Sea (Hurghada, Egypt) based on remote sensing, EARSeL eProceedings 2/2004, pp 191-207

[28] Wahid A.M. (2008) GIS-based modeling of windtransported sand on the Qaa plain beach, Southwestern Sinai, Egypt, Journal of Coastal Research, Vol. 24, No. 4, pp. 936-943. DOI: 10.2112/06-0733.1

[29] Wahid A., Madden M., Khalaf F., Fathy I. (2009). Land suitability scenarios for arid coastal plains using GIS modeling: Southwestern Sinai coastal plain, Egypt, Journal of Urban and Environmental Engineering (JUEE), Vol. 3, No. 2, pp. 73-83. DOI: 10.4090/juee.2009.v3n2.073083

[30] Wahid A., Madden M., Khalaf F., Fathy I. (2016). Geospatial analysis for the determination of hydromorphological characteristics and assessment of flash flood potentiality in arid coastal plains: A case in southwestern Sinai, Egypt, Earth Sci. Res. J., Vol. 20, No. 1, pp 1-9. DOI: 10.15446/esrj.v20n1.49624 